Mińko Alicja, Hilicka Zuzanna, Stępień Paulina, Bereda Zuzanna. Sports injuries in indoor volleyball in people who play professionally and as a hobby. Journal of Education, Health and Sport. 2021;11(8):101-108. eISSN 2391-8306. DOI http://dx.doi.org/10.12775/JEHS.2021.11.08.011

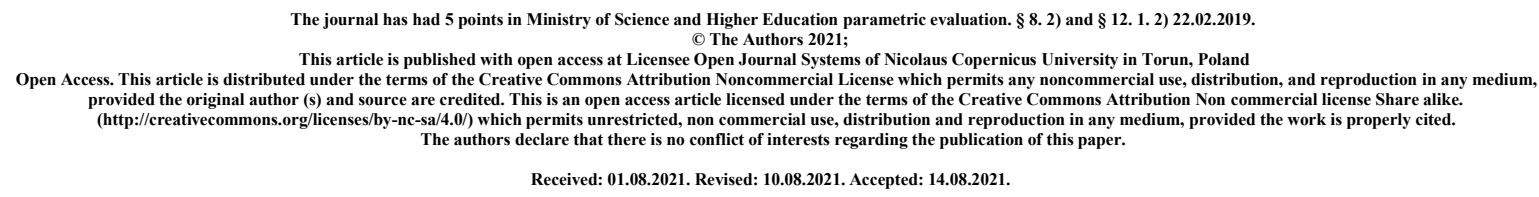

\title{
Sports injuries in indoor volleyball in people who play professionally and as
} a hobby

\author{
Alicja Mińko \\ ORCID iD https://orcid.org/0000-0003-2299-3958 \\ Affiliation Department of Medical Rehabilitation and Clinical Rehabilitation, Pomeranian \\ Medical University, 71-210 Szczecin \\ Country Poland \\ Bio Statement - \\ Principal contact for editorial correspondence.
}

\section{Zuzanna Hilicka}

ORCID iD https://orcid.org/0000-0001-8137-8555

Affiliation Student Science Club "KINEZIS" of the Department of Medical Rehabilitation and Clinical Physiotherapy, Pomeranian Medical University, 71-210, Szczecin

\author{
Country Poland
}

Bio Statement -

\section{Paulina Stępień}

Affiliation Student Science Club "KINEZIS" of the Department of Medical Rehabilitation and Clinical Physiotherapy, Pomeranian Medical University, 71-210, Szczecin
Country
Poland

Bio Statement -

\section{Zuzanna Bereda}

Affiliation Student Science Club "KINEZIS" of the Department of Medical Rehabilitation and Clinical Physiotherapy, Pomeranian Medical University, 71-210, Szczecin
Country
Poland

Bio Statement - 


\begin{abstract}
Introduction: Volleyball is a sport that causes injuries very often. They often result from the lack of an appropriate warm-up, the intensity of exercises that do not match the body's capabilities, or the use of inadequate techniques and poorly selected sports equipment. The aim of the study was to compare the injuries of people who play volleyball professionally with people who play volleyball.
\end{abstract}

Material and methods: The research was conducted among 144 volleyball players - 75 women (52.08\%) and 69 men (47.92\%). They were in three age groups: 18-20, 21-25 and over 25 years of age. The group was divided according to the type of game, i.e. whether it is a professional $(49.31 \%)$ or a hobbyist $(50.69 \%)$. Each of the volleyball players completed the questionnaire.

Results: The group playing volleyball professionally comprised 71 people $(49.31 \%)$, while the amateur group comprised 73 people (50.69\%). Among people professionally training volleyball, injuries were observed in 64 (90.14\%) people, while among people training amateur volleyball, injuries occurred more often in as many as $70(95.89 \%)$ people. The most common trauma in the first and second groups was sprain, which occurred in the first group in $27(38.03 \%)$ people, and in the second group - $26(35.62 \%)$.

Conclusions: Sprains are the most common injuries among people who play volleyball professionally and as a hobby. Most people who play volleyball professionally after an injury benefited from rehabilitation.

Key words: volleyball; injuries, ankle joint; prevention

\title{
Introduction:
}

Volleyball is one of the most popular sports in the world. According to the literature, it ranks second after football in terms of world popularity. It is a team sport in which both women and men can participate. There are many volleyball teams - from amateur to professional. Volleyball is also an Olympic sport. There are two types of volleyball: indoor and beach volleyball. In indoor volleyball, the team consists of six players, while in beach volleyball - two. The motor skills of volleyball players are very similar in both types of game. The only difference is in the rules of the game, the dimensions of the pitch, the composition of the pitch and the environmental conditions $[1,2,3]$. As in any sport, players are exposed to the 
risk of injuries, both during training and matches. The incidence of injuries of the musculoskeletal system among volleyball players ranges from 1.7 to 10.7 injuries per 1000 hours of play $[2,4,5]$. According to the National Collegiate Athletic Association (NCAA), the most common injury in volleyball is ankle sprain. Then there are injuries to the knee joint, shoulder and lower spine $[6,7]$. Most injuries are related to repeated jumping and hitting the ball overhead. Volleyball is considered a "non-contact" sport. Compared to other sports, especially contact sports such as handball and hockey, volleyball has the lowest injury rate. Competitors at a high level are exposed to a greater risk of injuries and injuries mainly caused by overload, although their percentage is still relatively low $[1,8,9]$. Each of the injuries is a disadvantage for the player. The recovery time and complications can significantly affect the career of a volleyball player. A thorough analysis of the pattern of trauma as well as understanding and reducing the risk factors will allow for the selection of an optimal preventive program, which in turn will contribute to lowering the incidence of injuries [10]. The aim of this study was to compare the injuries of people who play volleyball professionally with those who play volleyball.

\section{Material and methods:}

144 volleyball players took part in the study - 75 women and 69 men. They were in three age groups: 18-20, 21-25 and over 25 years of age. The group was divided according to the type of game, i.e. whether it is a professional (group 1) or an amateur (group 2). The study used the original questionnaire, which included sociodemographic and volleyball questions. The respondents were asked about the type of game, length of training period, position on the pitch, and injuries. The survey also included questions about the circumstances of the injury, as well as the treatment used. The study group was gathered through internet forums associating people who play volleyball.

Statistical analysis was performed using the licensed Statistica 13 program (StatSoft, Inc. Tulsa, OK, USA). The normality of the distribution of quantitative data was assessed using the Shapiro-Wilk test. Quantitative data are presented as mean, standard deviation, median and evaluated using the Mann-Whitney U test. 


\section{Results:}

The group playing volleyball professionally comprised 71 people $(49.31 \%)$, while the amateur group comprised 73 people (50.69\%). Among people professionally training volleyball, injuries were observed in 64 (90.14\%) people, while among people training amateur volleyball, injuries occurred more often in as many as $70(95.89 \%)$ people. The most common trauma in the first and second groups was sprain, which occurred in the first group in $27(38.03 \%)$ people, and in the second group - 26 (35.62\%). The remaining types of injuries in groups 1 and 2 are presented in Figure 1.

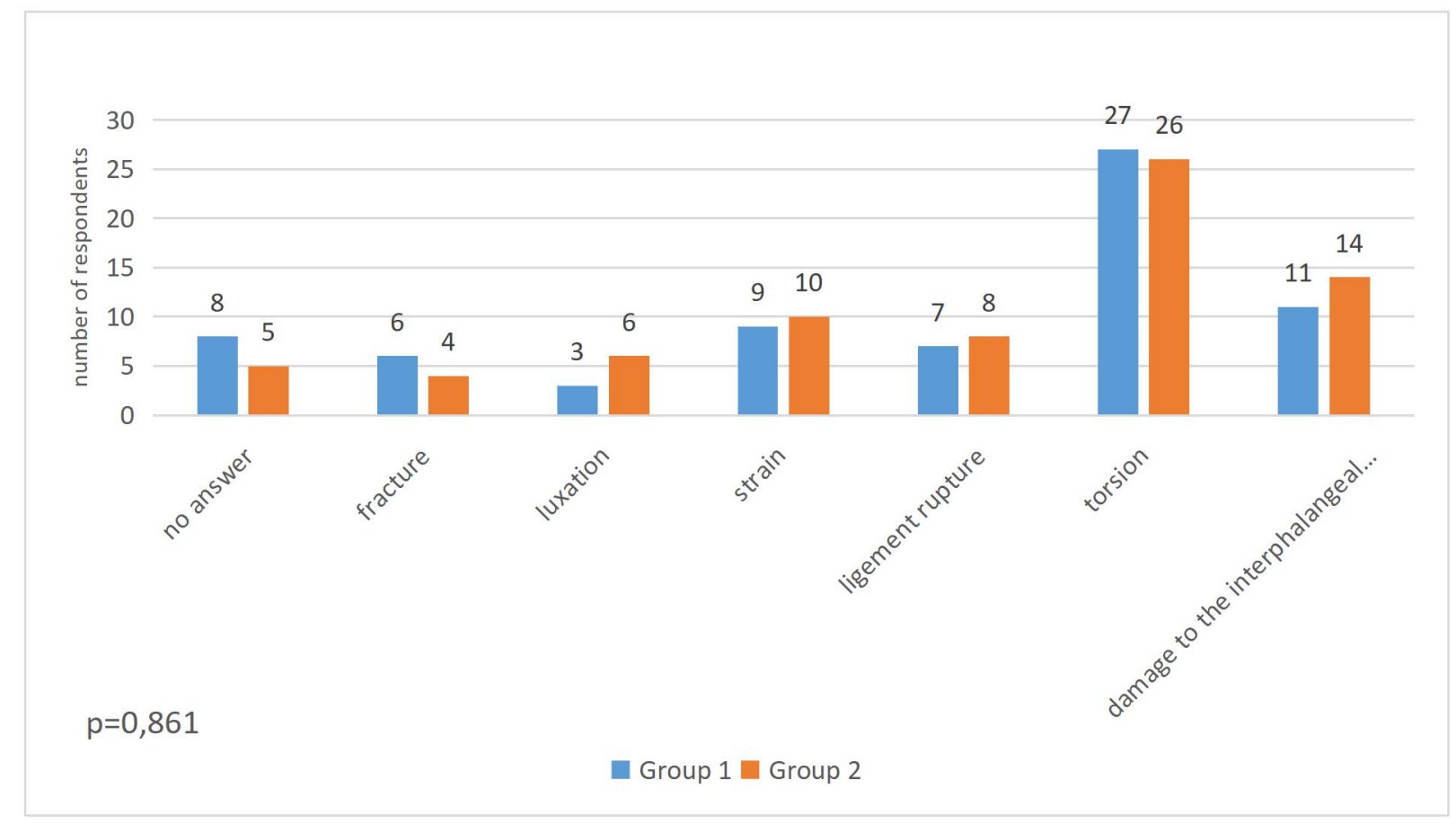

Figure 1. Types of injuries in groups 1 and 2.

In group 1 among $25(35.21 \%)$ people, the most common trauma was caused by landing after jump. A similar result was obtained in group 2, where 25 (34.25\%) people suffered from an injury during landing after jump. Detailed results are presented in Figure 2. 


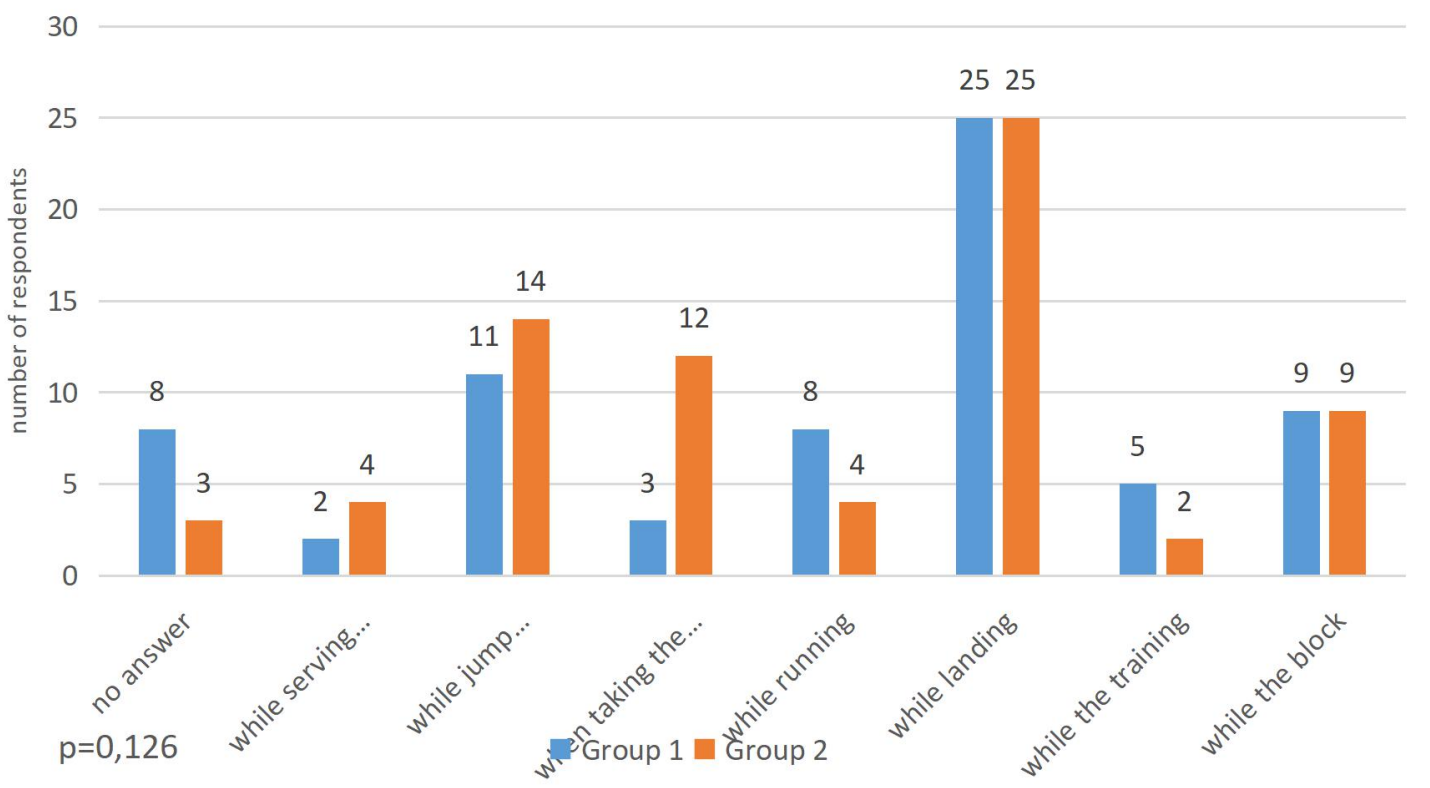

Figure 2. The circumstances of the injury in group 1 and 2.

The ankle joint was the most common site of injury in both study groups (Figure 3).

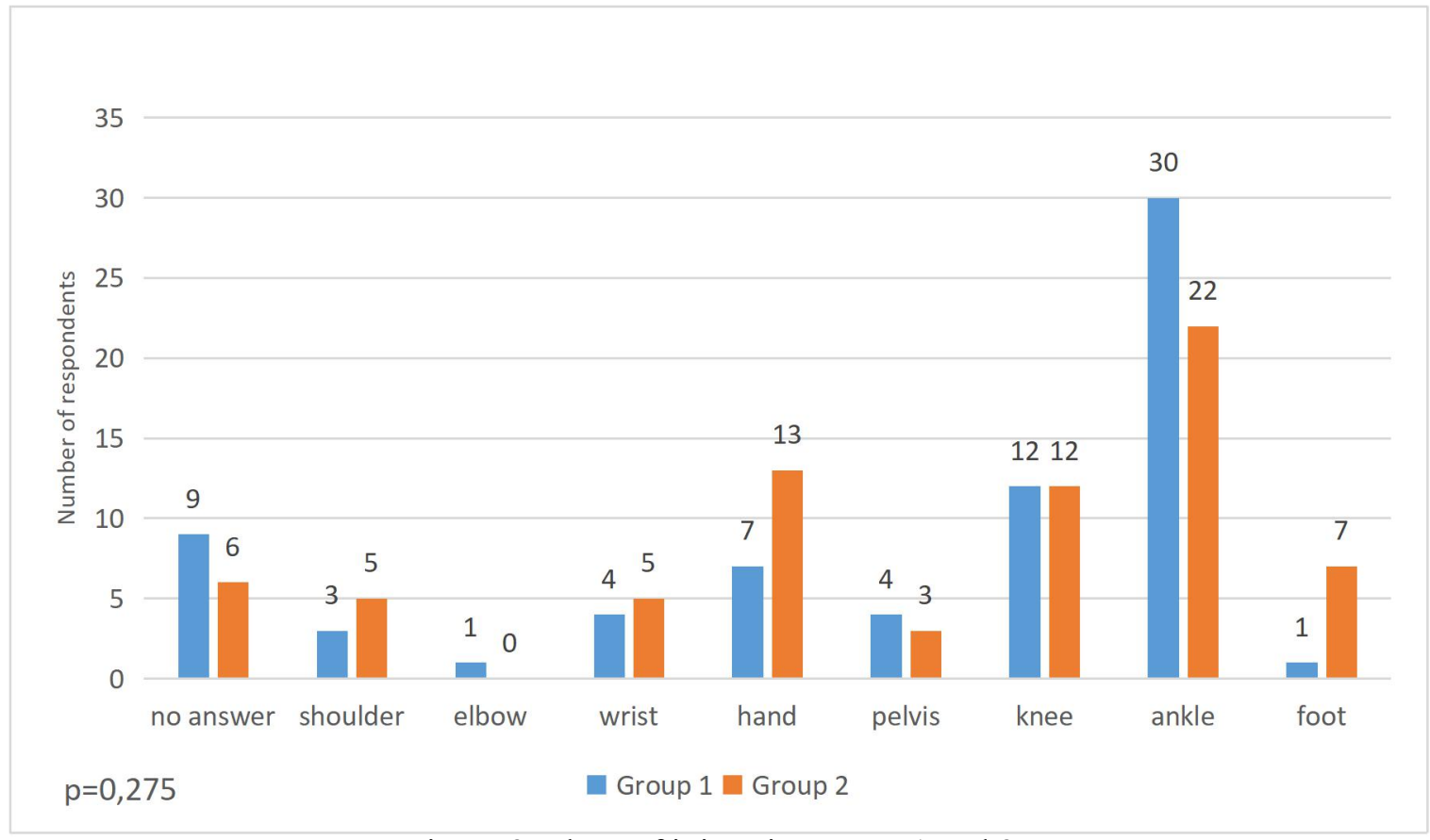

Figure 3. Place of injury in groups 1 and 2. 
After the injury, most of the people in the first group underwent rehabilitation as basic treatment - $46(64.79 \%)$ people. In turn, in the second group only $31(42.47 \%)$ had rehabilitation. As many as $22(30.14 \%)$ people did not undertake any treatment $(p=0.003)$. The results are presented in Figure 4.

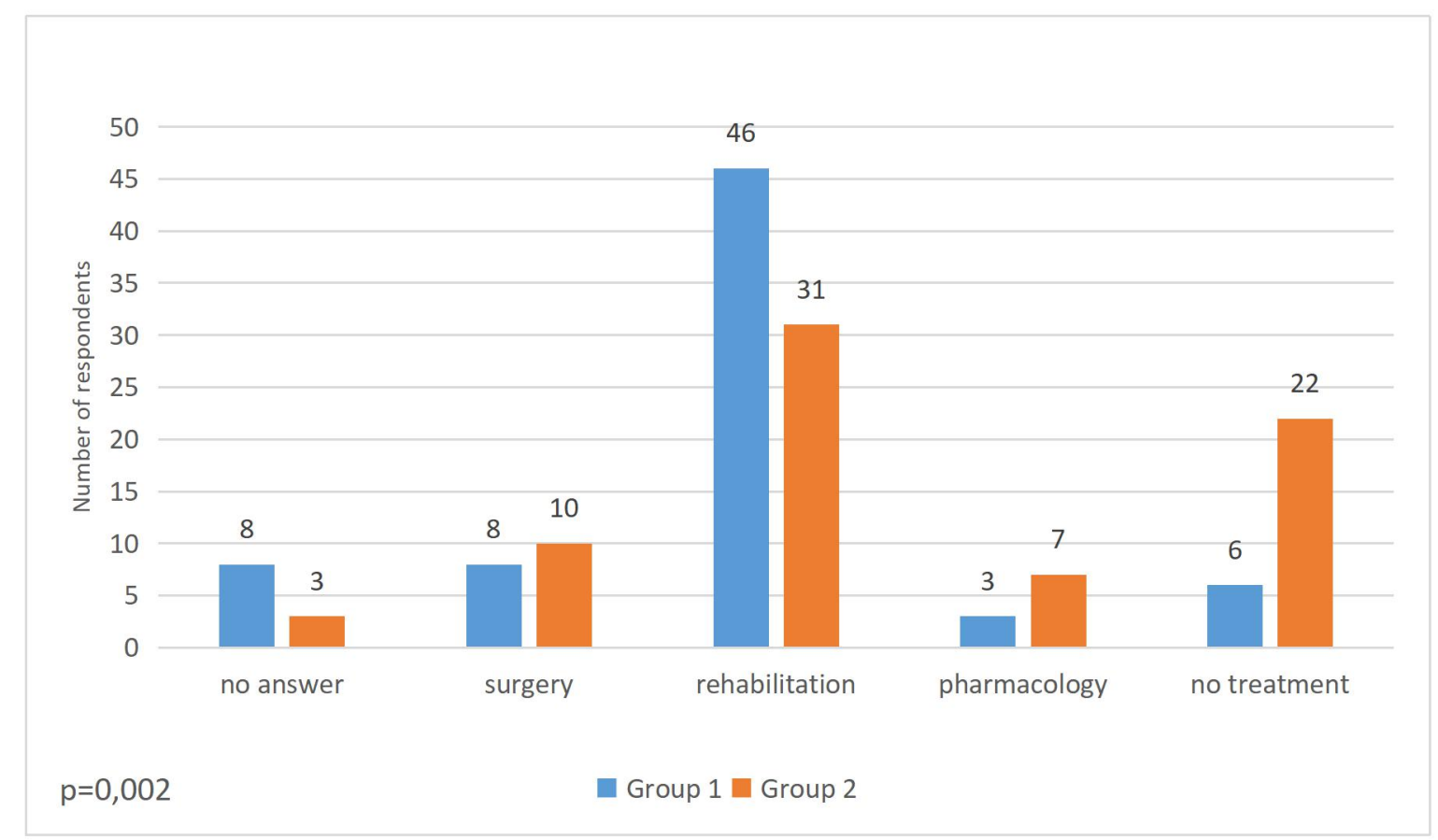

Figure 4. Type of treatment in group 1 and 2.

\section{Discussion:}

Volleyball is a sport that involves injuries very often. The aim of this study was to compare the injuries of people who play volleyball professionally with those who play volleyball.

Cieśla and co-authors conducted similar research in a group of professional volleyball players. According to their results, $87 \%$ of respondents suffered at least one sport-related injury, with an average of 4.02 injuries per one volleyball player. The most common injuries were the ankle and knee joints. Typical injuries include: injuries of muscles, joints and ligaments, sprains and strains, as well as bruises [11].

Cuñado- González et al. Conducted a study among 490 volleyball players. The injury frequency in the study group was $66.9 \%$, and the average injury per player was 0.94 . The ankle and knee joints were the most frequently injured parts of the body. The most common types of injuries were sprains, tendinopathies and strains [12].

In their study, Pastor and co-authors studied 34 professional volleyball players. There were 186 injuries in the study group. The injury rate was 1.94 injuries per player. The 
incidence of acute injuries was $3.3 / 1000 \mathrm{~h}$ of the retina, and the incidence of overload injuries was $1.08 / 1000 \mathrm{~h}$ of the volleyball [13].

Chandran and co-authors conducted a study in which they tested volleyball players for the purpose identify emerging injury patterns in this population. The overall injury rate was 6.73 per 1,000 athlete exposures. The most common injuries were to the knee $(14.6 \%)$ and ankle (13.8\%). Most of the injuries were attributed to overload (26.1\%) or non-contact $(22.7 \%)$ mechanisms. The most frequently reported injury was a rupture of the lateral ligament complex of the ankle joint (11.1\%) [14].

\section{Conclusions:}

The most common injury among people who play volleyball professionally and as a hobby is sprains. Most people who play volleyball professionally after an injury benefited from rehabilitation.

\section{Literature:}

1. Reeser JC, Verhagen E, Briner WW, Askeland TI, Bahr R. Strategies for the prevention of volleyball related injuries. $\mathrm{Br} \mathrm{J}$ Sports Med. 2006;40(7):594-600. doi: 10.1136/bjsm.2005.018234.

2. Gouttebarge V, Zwerver J, Verhagen E. Preventing musculoskeletal injuries among recreational adult volleyball players: design of a randomised prospective controlled trial. BMC Musculoskelet Disord. 2017;2;18(1):333. doi: 10.1186/s12891-017-1699-6.

3. Baugh CM, Weintraub GS, Gregory AJ, Djoko A, Dompier TP, Kerr ZY. Descriptive Epidemiology of Injuries Sustained in National Collegiate Athletic Association Men's and Women's Volleyball, 2013-2014 to 2014-2015. Sports Health. 2018;10(1):60-69. doi: $10.1177 / 1941738117733685$.

4. Briner WW Jr, Kacmar L. Common injuries in volleyball. Mechanisms of injury, prevention and rehabilitation. Sports Med. 1997;24(1):65-71. doi: 10.2165/00007256199724010-00006.

5. Lesman J, Jóźwik M, Domżalski ME, Luceri A, Mangiavini L, Peretti GM, Luceri F. Sport injuries in professional volleyball players. J Biol Regul Homeost Agents. 2020;34:163-170.

6. Eerkes K. Volleyball injuries. Curr Sports Med Rep. 2012;11(5):251-6. doi: 10.1249/JSR.0b013e3182699037. 
7. Kilic O, Maas M, Verhagen E, Zwerver J, Gouttebarge V. Incidence, aetiology and prevention of musculoskeletal injuries in volleyball: A systematic review of the literature. Eur J Sport Sci. 2017;17(6):765-793. doi: 10.1080/17461391.2017.1306114.

8. James LP, Kelly VG, Beckman EM. Injury risk management plan for volleyball athletes. Sports Med. 2014;44(9):1185-95. doi: 10.1007/s40279-014-0203-9.

9. Verhagen EA, Van der Beek AJ, Bouter LM, Bahr RM, Van Mechelen W. A one season prospective cohort study of volleyball injuries. Br J Sports Med. 2004;38(4):477-81. doi: 10.1136/bjsm.2003.005785.

10. van Beijsterveldt AM, van de Port IG, Krist MR, Schmikli SL, Stubbe JH, Frederiks JE, et al.: Effectiveness of an injury prevention programme for adult male amateur soccer players: a cluster-randomised controlled trial. Br J Sports Med 2012;46(16):1114-1118.

11. Cieśla E, Dutkiewicz R, Mgłosiek M, Nowak-Starz G, Markowska M, Jasiński P, Dudek J. Sports injuries in Plus League volleyball players. J Sports Med Phys Fitness. 2015;55(6):62838.

12. Cuñado-González Á, Martín-Pintado-Zugasti A, Rodríguez-Fernández ÁL. Prevalence and Factors Associated With Injuries in Elite Spanish Volleyball. J Sport Rehabil. 2019;28(8):796-802. doi: 10.1123/jsr.2018-0044.

13. Pastor MF, Ezechieli M, Classen L, Kieffer O, Miltner O. Prospective study of injury in volleyball players: 6 year results. Technol Health Care. 2015;23(5):637-43. doi: 10.3233/THC-151009.

14. Chandran A, Morris SN, Lempke LB, Boltz AJ, Robison HJ, Collins CL. Epidemiology of Injuries in National Collegiate Athletic Association Women's Volleyball: 2014-2015 Through 2018-2019. J Athl Train. 2021;56(7):666-673. doi: 10.4085/1062-6050-679-20. 